\title{
Discussion: An attempt to monitor pore pressure changes in a block sample during and after sampling
}

\author{
H. A. AMUNDSEN*, J. JØNLAND*, A. EMDAL*, V. THAKUR*, J. Y. WON†, J. D. GREENWOOD†, \\ I. A. CONTRERAS $\uparrow$ and F. G. HERNANDEZ-MARTINEZ†
}

\author{
(c) 2017 Thomas Telford Ltd
}

CONTRIBUTION BY J. Y. WON, J. D. GREENWOOD, I. A. CONTRERAS AND F. G. HERNANDEZ-MARTINEZ The authors presented measured pore pressure changes during and after block sampling in a sensitive clay. The discussers believe that the attempt made a significant contribution to geotechnical understanding, especially for soft clay engineering. The reported pore pressure data are believed to be the first measured record to reveal details of stress changes during block sampling. The authors, however, did not fully address stress changes that occurred during the drilling and sampling processes. On the basis of the presented pore pressure data and descriptions of the drilling and sampling, the discussers developed effective stress paths in $\sigma_{\mathrm{h}}^{\prime}-\sigma_{\mathrm{v}}^{\prime}$ and $p^{\prime}-q$ spaces that show effective stress changes during installation, drilling, sampling, transport and laboratory testing. Anisotropic changes in total and effective vertical and horizontal stresses were thoroughly evaluated for the entire drilling and sampling processes. The assumed soil parameters $K_{0}=0.5$ and $A_{\mathrm{u}}=1 / 3$ that were used by the authors could be re-evaluated to ensure they are representative of the lightly over-consolidated characteristics of the Tiller clay. Those parameters have significant influence on the perfect sampling, the effective stress paths during the sampling, and the residual effective stress.

The developed effective stress paths show the complex stress changes (compression-extension-compression) over the drilling and sampling procedures indicating that most of the stress relief occurred during the drilling, prior to the sampling process. The practice of open borehole without mud, light density of the drilling mud and the downward rod pressures from the drilling operation created substantial positive and negative pore pressures, resulting in the compression and extension stress conditions. The effective stress paths also indicate that the sample approached the estimated extension failure envelope during the last stage of drilling. The measured pore pressures and the complex stress paths show that the conceptual and idealised stress paths during the drilling and sampling presented by others are far from reality. Overall, the total stress relief $\left(\sigma_{\mathrm{v}}=\sigma_{\mathrm{h}}=0\right)$ to the isotropic condition and volume change (swell) are apparent from the Sherbrooke sampling. The tube sampling would exhibit a different set of stress paths due to the radial constraint provided by the tube itself. The effective stress changes during stage 3 : augering $(3-7 \mathrm{~m})$ and stage 4: augering/remoulding (7-9 $\mathrm{m}$ ) could be reduced by keeping the mud in the borehole from the start of drilling and by increasing the mud density. In order to reduce the stress relief

Published online at www.geotechniqueletters.com on 22 December 2016.

*Department of Civil and Environmental Engineering, NTNU, Trondheim, Norway.

$\dagger$ 'Barr Engineering Co., Minneapolis, Minnesota, USA. and achieve a high residual effect stress, careful drilling operations and an increased mud density are recommended.

\section{AUTHORS' REPLY}

The authors welcome the comments from Dr. Won, Mr. Greenwood, Dr. Contreras and Dr. Hernandez-Martinez on their letter related to monitoring pore pressure changes during and after sampling of a soft soil mini-block sample.

The coefficient of the earth pressure at rest is defined as the ratio between the horizontal and vertical effective stresses, $K_{0}^{\prime}=\sigma_{\mathrm{h} 0}^{\prime} / \sigma_{\mathrm{v} 0}^{\prime}$, and is estimated to be $0 \cdot 50$ for the Tiller clay. The $K_{0}^{\prime}$ value is based on Jaky's equation, $K_{0}^{\prime}=1-\sin \phi$, where $\phi=29-30^{\circ}$ was determined based on consolidated anisotropically undrained compression (CAUC) triaxial testing (Gylland et al., 2013b). The $K_{0}^{\prime}$ value is in agreement with the Brooker \& Ireland (1965) correlation, which considers the influence of the loading history and plasticity. For highly sensitive clays, however, it is more common to use a higher $K_{0}^{\prime}$ value for triaxial testing (e.g. Sandven, 1990; Gylland et al., 2013b). $K_{0}$, defined as the ratio of the horizontal and vertical total stresses, is estimated to be 0.74 for the Tiller clay.

The assumption of the pore pressure coefficient $A_{\mathrm{u}}=1 / 3$ is based on the trixial test results from high-quality block samples from the Tiller clay (Gylland et al., 2013a, 2013b; Emdal et al., 2016; Amundsen et al., 2017), where the samples display a dilatancy close to zero in the stress path prior to the peak undrained shear strength. This indicates an approximately elastic response of the clay, for which the given value of $A_{\mathrm{u}}$ is reasonable.

The discussers highlight that the stress changes that occurred during the drilling and sampling processes are not fully addressed in the authors' paper, and they also present some concerns about the procedures. In Fig. 1, they present an effective stress path which indicates that most of the stress relief occurs during the drilling, prior to the sampling.

The drilling process has been set-up to minimise the stress cycles in the sample, primarily by keeping the borehole filled with water and mud during the entire process. However, the authors here note that the mud level did fall to as much as $2 \mathrm{~m}$ below the terrain level for limited periods of time. This occurred during the early parts of the sampling process, and hence it is reasonable to assume that the sample is not significantly affected. To clarify this process, a more detailed description of the installation, augering and sampling follows, with an illustration shown in Fig. 2.

\section{Installation}

Prior to the installation of the piezometer, the borehole was preaugered $2 \mathrm{~m}$ and a casing was installed to stabilise the upper part of the borehole. The borehole was thereafter filled with water, point (0) in Figs 2(a) and 2(b). Inside the borehole, a guide was placed to avoid horizontal movements 


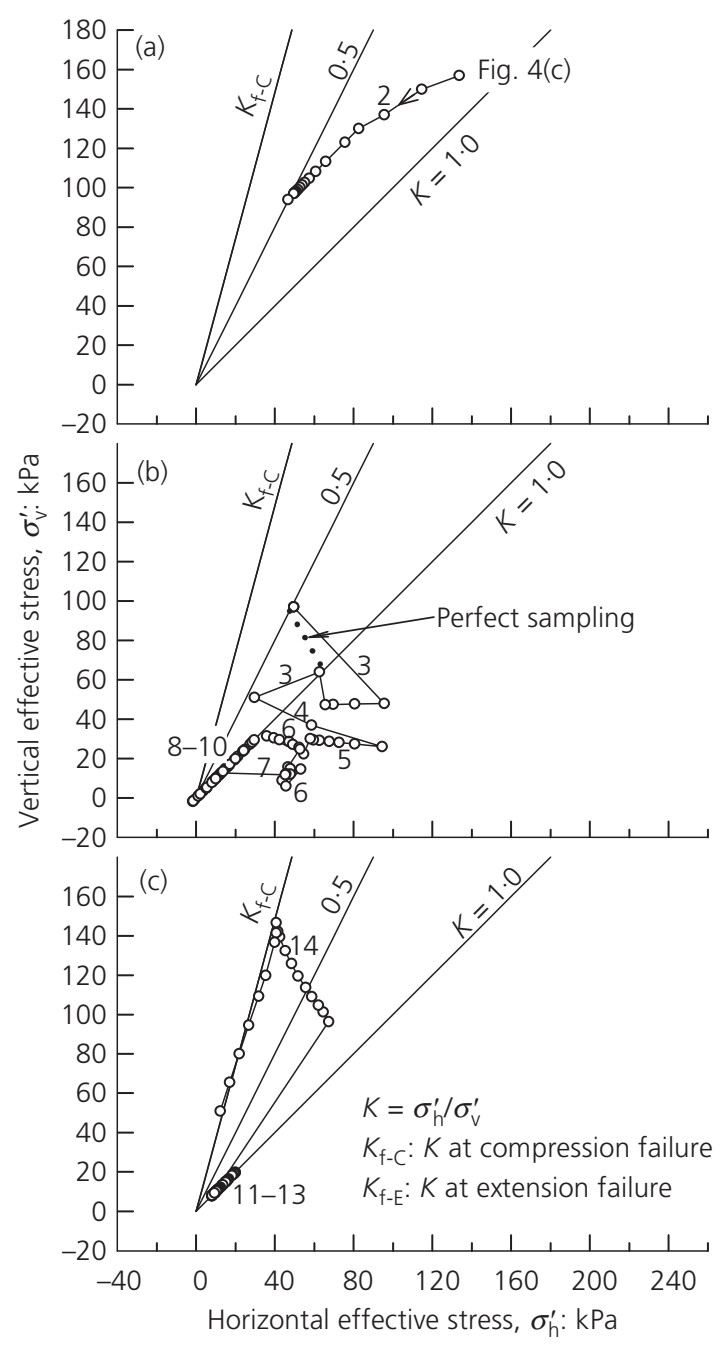

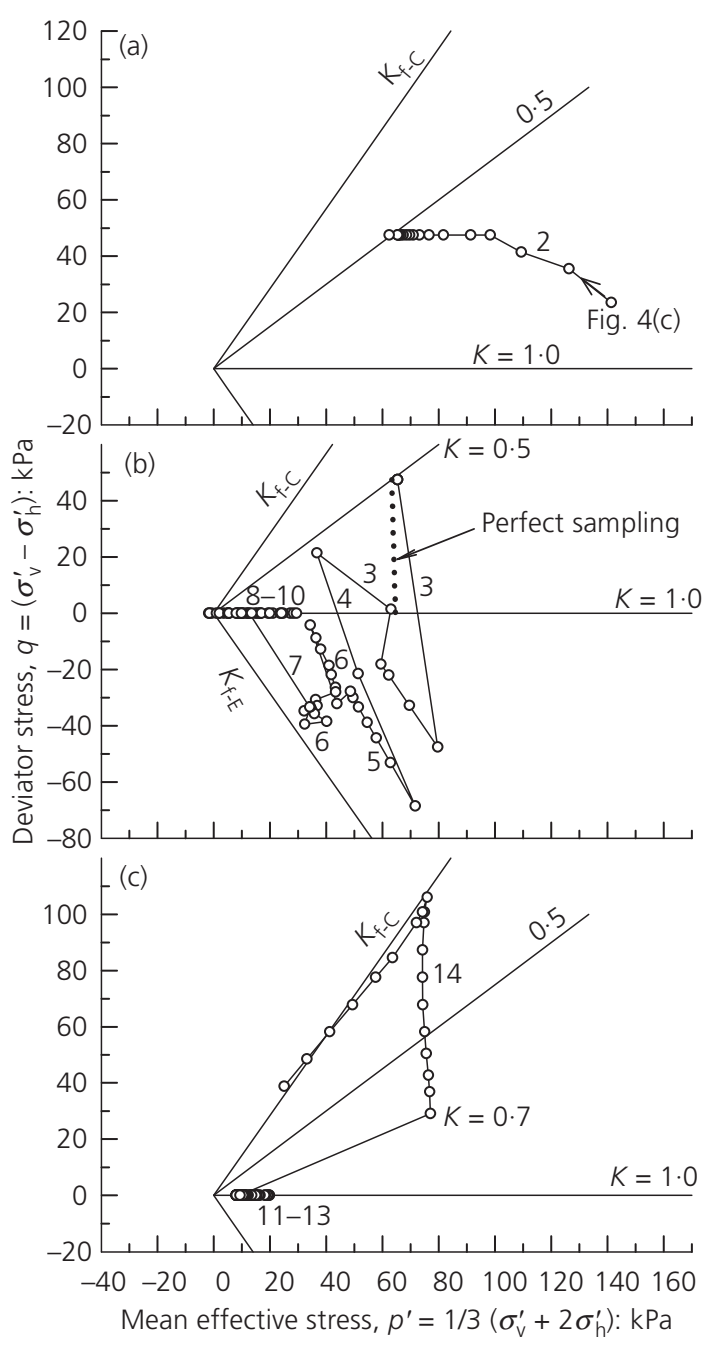

2: Pore pressure stabilisation

4: Augering/remoulding (7-9 m)

6: Two dummy block sampling starts

8: Cutting finished

10: Above ground

12: Transport

14: CAUC shearing

Fig. 1. Stress changes in the clay from installation of the piezometer to laboratory testing. (a) Piezometer installation, (b) drilling and sampling and (c) transport and laboratory testing. Contributed by J. Y. Won, J. D. Greenwood, I. A. Contreras and F. G. Hernandez-Martinez

of the installation rod during the insertion of the piezometer. This guide was removed after the piezometer was installed. The installation of the piezometer at a depth of $10 \mathrm{~m}$ caused some pore pressure fluctuations. The vertical and horizontal total stresses were assumed to be unchanged at this stage. The authors believe that this is reasonable due to the fact that the insertion of the piezometer, which was much smaller than the volume to be extracted as a mini-block sample, has a negligible effect on its surroundings. In other words, no unloading was to be expected at this stage and the pore pressure stabilised at the in situ level. Points (1)-(2) in Figs 2(a) and 2(b), therefore, illustrate the stabilisation of the pore pressure back to the in situ level of $93 \mathrm{kPa}$. The in situ effective vertical stress, $\sigma_{\mathrm{v} 0}^{\prime}$, was $97 \mathrm{kPa}$ and the mean effective stress, $p_{0}^{\prime}$, was $64.7 \mathrm{kPa}$ at a depth of $10 \mathrm{~m}$.

\section{Drilling: augering}

The drilling started $33 \mathrm{~h}$ after the installation of the piezometer and reached a depth of $10 \mathrm{~m}$ within one day.
To achieve this, the soil from a depth of 2 to $7 \mathrm{~m}$ was removed with an auger, $1 \mathrm{~m}$ at a time, and water was added through the central part of the drill rod and the tip of the auger. When the augering reached a depth of $7 \mathrm{~m}$, the mud level was about 1-2 $\mathrm{m}$ below the ground. The augering process caused no changes in the measured pore pressure at $10 \mathrm{~m}$, see (3)-(4), Fig. 5 (Amundsen et al., 2017).

At the depth of the piezometer, $3 \mathrm{~m}$ below the bottom of the borehole, the soil is assumed to be unaffected by the excavation of the borehole, which had a limited diameter of $25 \mathrm{~cm}$.

\section{Drilling: remoulding/augering}

The high-sensitive clay between 7 and $9 \mathrm{~m}$ was remoulded with an auger and only a small amount of the soil was removed from this depth. Therefore, only a minor change in total stresses is assumed. It is emphasised that the borehole was never emptied of mud, but the process of removing the soil with an auger caused the mud level to 

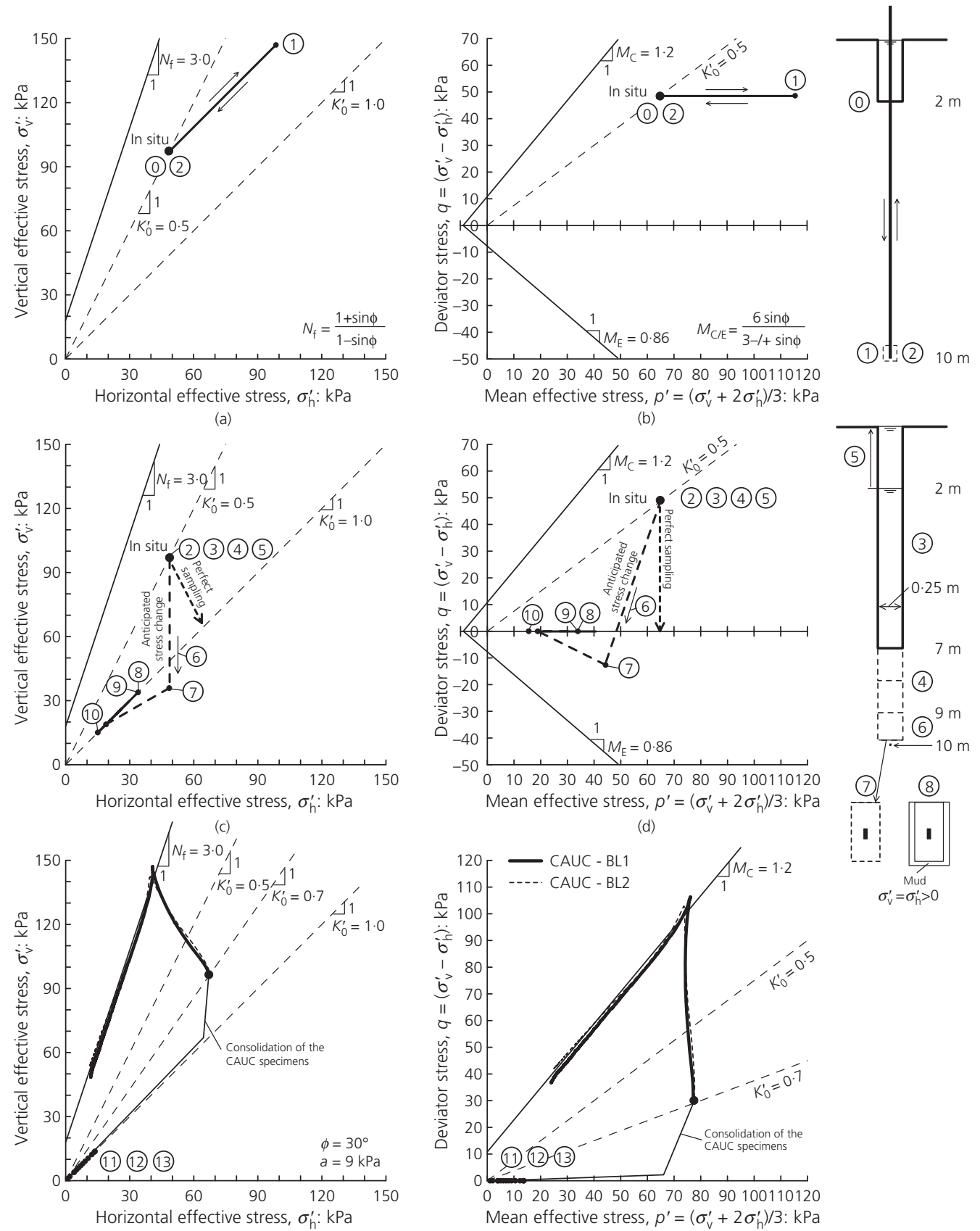

(0) Preaugering $-2 \mathrm{~m}$
(1) Installation of piezometer
(2) Pore pressure has stabilised at $u_{0}$
(3) Augering $(2-7 \mathrm{~m})-$ removing soil
(4) Augering/remoulding $(7-9 \mathrm{~m})$
(5) Filling borehole with water (water level $\sim 0 \mathrm{~m}$ )
(6) Dummy block sampling - removing soil

(7) Cutting started - block sample at 9.85-10.25 m

(8) and (9) Cutting finished and lifting starts

(10) Above ground

(11) Sealing sample

(12) Transport

(13) In the laboratory

Fig. 2. Anticipated stress changes in the mini-block sample, from installation of the piezometer to laboratory testing. (a) and (b) Piezometer installation; (c) and (d) drilling and sampling, where (3)-(7) represent the anticipated stress changes; (e) and (f) transport, storage and laboratory testing. Contributed by H. A. Amundsen, J. Jønland, A. Emdal and V. Thakur. $K_{0}^{\prime}$, coefficient of the earth pressure at rest; $N_{\mathrm{f}}$, inclination of the failure line in $\sigma_{\mathrm{h}}^{\prime}-\sigma_{\mathrm{v}}^{\prime}$ stress space; $\phi$, friction angle; $M_{\mathrm{C} / \mathrm{E}}$, inclination of the failure line in $p^{\prime}-q$ stress space, undrained compression/extension; a, attraction

decrease by about 1-2 $\mathrm{m}$. This was compensated for by refilling with water.

The fluctuations in the pore pressure measurements may occur during drilling, some of which are accidental and should be avoided. For example, the large peak in the pore pressure, see point (4) in Fig. 5 by Amundsen et al., 2017, was caused by a piece of sensitive clay slipping off the auger during lifting out from the borehole. The drops in the measured pore pressure (see (4) in Fig. 5 by Amundsen et al., 2017) were caused by the auger, which got slightly clogged up with remoulded clay that hindered water flow through the tip. 


\section{Dummy sampling}

From the $9 \mathrm{~m}$ depth until the piezometer was reached at $10 \mathrm{~m}$, the mini-block sampler was used to extract the soil, see (6) in Figs 2(c) and 2(d).

During the carving of the dummy mini-block samples, some fluctuations in the pore pressure were measured, see Fig. 5 (Amundsen et al., 2017). This may have been caused by the sampler pushing on the bottom of the borehole. At this point in the drilling process, the deeper part of the borehole (about 7-9 m) was full of remoulded highly sensitive clay $\left(\gamma=17-19 \mathrm{kN} / \mathrm{m}^{3}\right)$, with the exception of a few intact lumps that also contributed to the spike in the pore pressure. In addition, releasing the knives to cut the bottom of the first dummy sample was difficult due to the resistance in the remoulded clay. These clay lumps were visible when the dummy mini-block sample, which was covered in remoulded clay, was lifted to the surface. Further sampling was done after the pore pressure, measured by the piezometer, had stabilised. The second dummy sample was extracted normally, with minimal changes in the pore pressure (see Fig. 5, Amundsen et al., 2017).

It is emphasised that block sampling remoulds some of the highly sensitive clay, which adds to the mud density in the borehole. The unit weight of the mud in the borehole was estimated to be about $11 \mathrm{kN} / \mathrm{m}^{3}$ at $0-7 \mathrm{~m}$ depth, about $18 \mathrm{kN} / \mathrm{m}^{3}$ at $7-9 \mathrm{~m}$ and about $16 \mathrm{kN} / \mathrm{m}^{3}$ at $9-10 \mathrm{~m}$. This amounted to $129 \mathrm{kPa}$ in total vertical stress, $\sigma_{\mathrm{v}}$, at a depth of $10 \mathrm{~m}$.

The stress path between (2) and (7) shows the anticipated stress changes in Figs 2(c) and 2(d). The vertical stress change between (2) and (7) was estimated to be about $61 \mathrm{kPa}$. This represents the degree to which the soil at a depth of $10 \mathrm{~m}$ was influenced by the borehole excavation, starting at a depth of $9-10 \mathrm{~m}$. The stress changes are assumed to be small at $10 \mathrm{~m}$ depth caused by the borehole excavation above 9-10 $\mathrm{m}$.

\section{Sampling}

At the bottom of the borehole, prior to the sampling, (7) in Fig. 2, the estimated stresses were as follows: $\sigma_{\mathrm{v}}^{\prime}=35.9 \mathrm{kPa}$, $\sigma_{\mathrm{h}}^{\prime}=48.5 \mathrm{kPa}, p^{\prime}=44.3 \mathrm{kPa}$ and $q=-12.6 \mathrm{kPa}-$ well below the extension failure line as shown in point (7) in Figs 2(c) and 2(d). Accordingly, $\Delta p=20 \cdot 4 \mathrm{kPa}$ from (2) to (7) in Figs 2(c) and 2(d), and hence most of the stress relief did not occur at this stage. It is assumed that the soil kept the in situ horizontal stress $\left(\sigma_{\mathrm{h}}=141.5 \mathrm{kPa}\right)$, but the vertical stress reduced to the mud pressure $\left(\sigma_{\mathrm{v}}=129 \mathrm{kPa}\right)$, which gave close to an isotropic stress state at the bottom of the borehole.

The carving of the mini-block sample, see (7)-(8) in Figs 2(c) and 2(d), caused a reduction of the horizontal stresses to the mud pressure, resulting in a perfectly isotropic stress state where $\sigma_{\mathrm{v}}=\sigma_{\mathrm{h}}=129 \mathrm{kPa}$ and $p^{\prime}=34 \mathrm{kPa}$. When the sample was lifted up the first 0.5-2 $\mathrm{m}$, the surrounding pressure decreased rapidly as the sample was coming out of the thick mud. For the remaining distance to the surface $\gamma_{\text {mud }}$ was assumed to be about $11 \mathrm{kN} / \mathrm{m}^{3}$, as illustrated in Fig. 8 by Amundsen et al. (2017).

Most of the stress relief occurred during the lifting of the mini-block sample out from the borehole, see (9)-(10) in Figs 2(c) and 2(d). At the surface, the total stresses were zero and the residual effective stress was $14 \mathrm{kPa}$ inside the sample.

\section{CLOSING REMARKS}

A detailed investigation of stress changes inside the miniblock sample suggests that the sample was neither subjected to complete total stress relief prior to the sampling nor subjected to extension failure during the drilling process. In line with the discussers, the authors also recognise the significance of the mud density in terms of borehole stability (Ladd \& DeGroot, 2003) and the total stress relief inside mini-block samples during the sampling process.

\section{REFERENCES}

Amundsen, H. A., Jønland, J., Emdal, A. \& Thakur, V. (2017). An attempt to monitor pore pressure changes in a block sample during and after sampling. Géotech. Lett. 7, No. 2.

Brooker, E. W. \& Ireland, H. O. (1965). Earth pressures at rest related to stress history. Can. Geotech. J. 2, No. 1, 1-15.

Emdal, A., Gylland, A., Amundsen, H. A., Kåsin, K. \& Long, M. (2016). Mini-block sampler. Can. Geotech. J. 53, No. 8, $1235-1245$.

Gylland, A., Jostad, H., Nordal, S. \& Emdal, A. (2013a). Micro-level investigation of the in situ shear vane failure geometry in sensitive clay. Géotechnique 63, No. 14, 1264-1270.

Gylland, A., Long, M., Emdal, A. \& Sandven, R. (2013b). Characterisation and engineering properties of Tiller clay. Engng Geol. 164, 86-100.

Ladd, C. C. \& DeGroot, D. J. (2003). Recommended practice for soft ground site characterization: Arthur Casagrande lecture. In Proceedings of the 12th PCSMGE, MIT, Cambridge, MA, USA.

Sandven, R. (1990). Strength and deformation properties of fine grained soils obtained from piezocone tests. PhD thesis, NTH (now NTNU). 